\title{
Introduction to MSME Products in Sidoarjo Regency Using Augmented Reality
}

\section{Pengenalan Produk UMKM Yang Ada Di Kabupaten Sidoarjo Menggunakan Augmented Reality}

\author{
Moch. Nur Huda ${ }^{1)}$, Sumarno *2) \\ \{nurhuda253@umsida.ac.id ${ }^{1)}$, sumarno@umsida.ac.id*2) \\ ${ }^{1,2)}$ Program Studi Informastika Fakultas Saintek, Universitas Muhammadiyah Sidoarjo
}

\begin{abstract}
Explanation of UMKMs (Micro, Small, and Medium Enterprises) is a business that has a very important role in the economy of a country, both in terms of the existing in the field of employment or created in terms of the number of businesses that exist. Explanation of UMKMs in terms of micro enterprises can also be interpreted as businesses owned by individuals or a productive economic business entity in accordance with the criteria of various micro, small, and medium enterprises. The purpose of this research is so that students can design an application that is able to display $3 D$ objects of UMKM products, and also to introduce UMKM products to consumers more easily and more efficiently. The method used is marked based tracking, then used as a marker is a card with a picture of UMKM products, and also augmented reality is using vuforia library as a database of UMKM product identifiers displayed, and unity engine software using the C\# programming language. The result of the research obtained is an augmented reality application that can bring up UMKM products in the form of a virtual 3-dimensional object display. The benefit of this research is that the augmented reality application of UMKM products can make it easier for manufacturers to introduce their products to consumers.
\end{abstract}

Keyword - Augmented Reality; Unity; UMKM; C\#.

\begin{abstract}
Abstrak. Penjelasan UMKM (Usaha Mikro, Kecil, dan Menengah) ialah usaha yang mempunyai peranan sangat penting dalam perekonomian suatu negara, baik dari segi sisi yang ada di lapangan pekerjaan ataupun yang tercipta dari segi sisi jumlah usaha yang ada. Penjelasan UMKM dari segi usaha mikro dapat diartikan juga usaha yang dimiliki perseorangan ataupun sebuah badan usaha ekonomi produktif yang sesuai dengan kriteria dari berbagai usaha mikro, kecil, maupun menengah. Tujuan dari penelitian ini adalah agar mahasiswa dapat merancang sebuah aplikasi yang mampu menampilkan objek $3 D$ produk UMKM, dan juga untuk memperkenalkan produk UMKM pada konsumen dengan lebih mudah dan lebih efisien. Adapun metode yang di gunakan ialah marked based tracking, kemudian yang digunakan sebagai marker ialah kartu yang bergambar produk UMKM, dan juga augmented reality ini menggunakan library vuforia sebagai database pengenal produk UMKM yang di tampilkan, dan software unity engine menggunakan Bahasa pemrograman C\#. Hasil dari penelitian yang didapatkan ialah sebuah aplikasi augmented reality yang dapat memunculkan produk UMKM berupa tampilan objek 3 dimensi virtual. Manfaat dari penelitian ini ialah dengan adanya aplikasi augmented reality produk UMKM ini dapat memudahkan produsen untuk mengenalkan produk mereka pada konsumen.
\end{abstract}

Kata Kunci - Augmented Reality; Unity; UMKM; C\#.

\section{PENDAHULUAN}

Penjelasan UMKM (Usaha Mikro, Kecil, dan Menengah) ialah usaha yang mempunyai peranan sangat penting dalam perekonomian suatu negara, baik dari segi sisi yang ada di lapangan pekerjaan ataupun yang tercipta dari segi sisi jumlah usaha yang ada. Penjelasan UMKM dari segi usaha mikro dapat diartikan juga usaha yang dimiliki perseorangan ataupun sebuah badan usaha ekonomi produktif yang sesuai dengan kriteria dari berbagai usaha mikro, kecil, maupun menengah. Penjelasan UMKM dari segi usaha kecil dapat diartikan suatu usaha ekonomi produktif independen atau yang berdiri sendiri dengan baik dan dimiliki perseorangan maupun sebuah kelompok dan bukan sebagai sebuah badan usaha yang bercabang dari suatu perusahaan. Dikuasai serta dimiliki dan menjadi bagian baik secara langsung maupun secara tidak langsung dari segi usaha menengah yang ada di suatu usaha. Penjelasan UMKM dari segi usaha menengah dapat diartikan suatu usaha ekonomi produktif serta bukan juga merupakan suatu cabang ataupun suatu anak usaha dari perusahaan pusat yang menjadi suatu bagian baik secara langsung maupun secara tidak langsung terhadap suatu usaha kecil ataupun suatu usaha besar dan memiliki total kekayan bersih atau murni sesuai yang telah diatur dalam aturan perundang-undangan.

Augmented reality adalah sebuah teknologi visual yang menggabungkan dunia virtual dengan dunia nyata secara real time dengan menggunakan kamera sebagai medianya. 
Mengacu pada permasalahan yang telah diuraikan di atas, maka diperlukan sebuah aplikasi yang dapat membantu untuk memperkenalkan produk UMKM ada di kabupaten Sidoarjo dengan memanfaatkan teknologi Augmented reality, dengan demikian diharapkan dapat membantu mempermudah produsen UMKM untuk mengenalkan produk mereka pada konsumen.

\section{METODE PENELITIAN}

\section{A. Lokasi dan waktu penelitian}

Penelitian aplikasi Pengenalan produk UMKM dilakukan di beberapa tempat pembuatan produk UMKM yang ada di Kabupaten Sidoarjo.

\section{B. Tahap pengumpulan data}

1. Data sekunder

Data ini didapatkan menggunakan buku-buku sebagai referensi untuk mendapatkan konsep teoritis dalam menganalisa data yang akan menjadi objek penelitian.

2. Observasi

Proses uji coba pengkodean menggunakan Augmented Reality SDK, pemodelan 3D menggunakan blender dan pembuatan desain marker kartu bergambar produk UMKM.

\section{Tahap perancangan sistem}

Dalam perancangan sistem ada beberapa tahapan yang harus dilakukan, berikut ini tahapannya :

1. Flow Chart

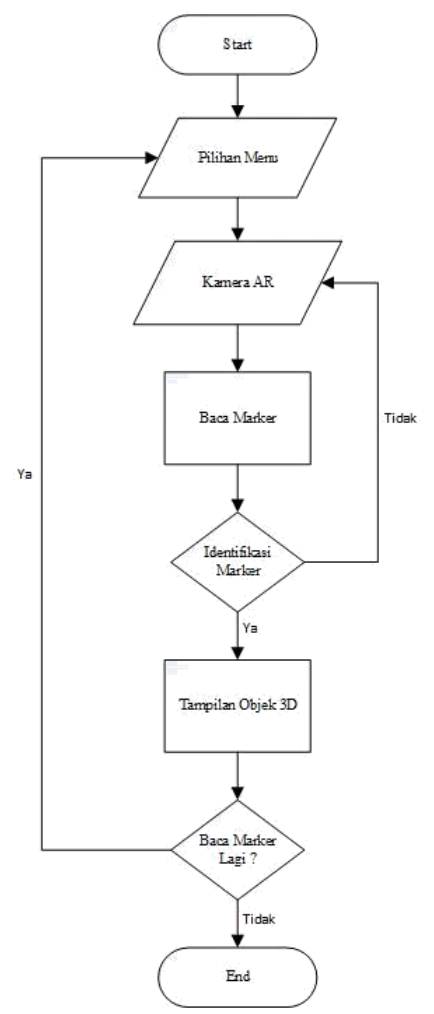

Gambar 1. Flowchart Diagram

2. Usecase Diagram

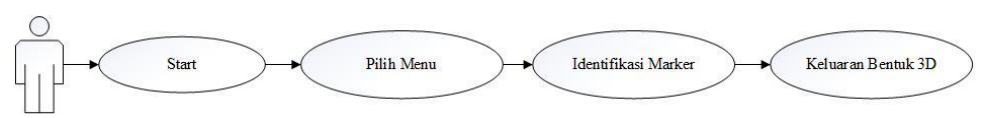

Gambar 2. Usecase 
Procedia of Engineering and Life Science Conference Vol. 1. No. 1 March 2021

Seminar Nasional \& Call Paper Fakultas Sains dan Teknologi (SENASAINS $1^{\text {st) }}$

Universitas Muhammadiyah Sidoarjo

3. Activity Diagram

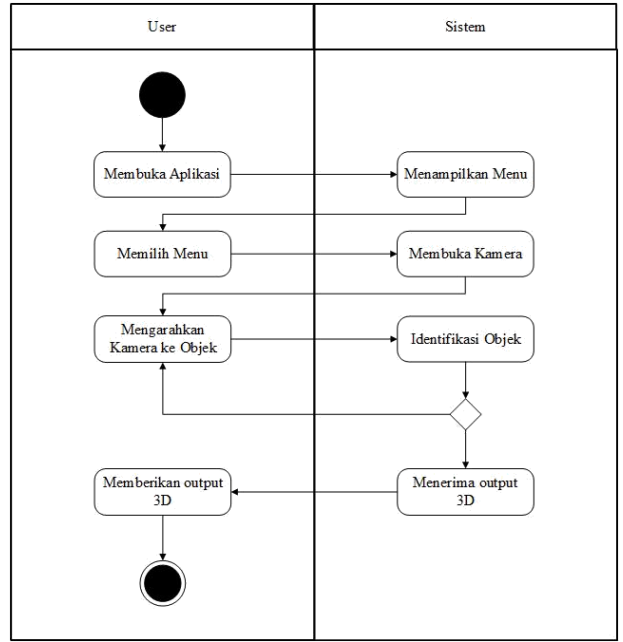

Gambar 3. Activity

\section{HASIL DAN PEMBAHASAN}

\section{A. Hasil penelitian}

Hasil dari penelitian yang didapatkan ialah :

1. Sebuah aplikasi augmented reality yang dapat memunculkan produk UMKM berupa tampilan objek 3 dimensi virtual.

2. Aplikasi augmented reality produk UMKM ini dapat memudahkan produsen untuk mengenalkan produk mereka pada konsumen.

\section{B. Pembahasan}

Desain Interface Aplikasi

Tampilan desain interface pada Gambar 4 merupakan halaman pertama yang muncul pada saat user membuka aplikasi, yang berisi tiga menu yaitu menu produk, tentang dan menu exit..

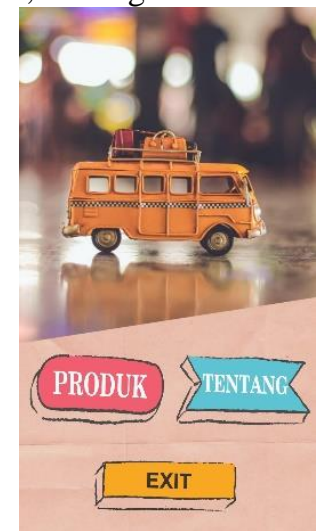

Gambar 4. Desain Interface

Tampilan Tentang

Tampilan tentang pada Gambar 5 berisi biodata data diri dari pembuat aplikasi dan terdapat tujuan dari pembuatan aplikasi augmented reality produk UMKM ini. 


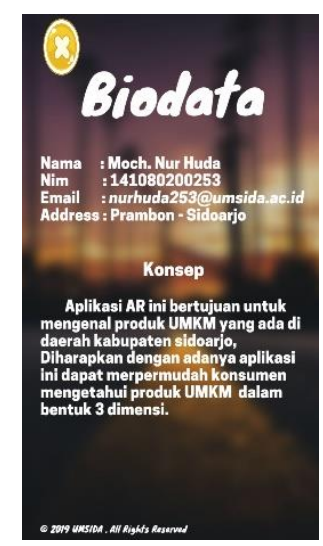

Gambar 5. Tentang

Tampilan Scan Produk

Gambar 6 ialah kamera akan mengenali objek yang ada di database vuforia. Seteleh kamera mengenali objek maka aplikasi akan memberikan output berupa gambar 3 dimensi yang menunjukan objek tersebut.

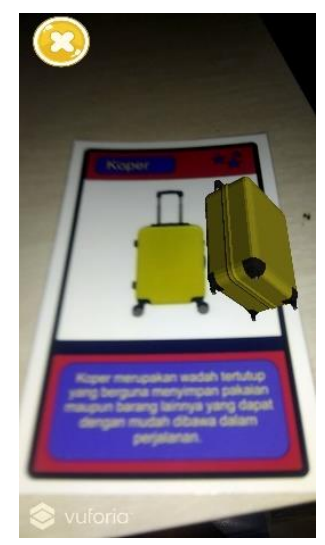

Gambar 6. Scan Produk

\section{Pengujian Aplikasi}

Pengujian aplikasi merupakan tahap pertama pengujian perangkat lunak. Dimana pengujian dilakukan untuk menguji fungsionalitas perangkat lunak per unit.

\begin{tabular}{|c|cc|c|c|c|}
\hline NO & Nama & Hasil Diharapkan & Hasil Didapatkan & Ketercapaian \\
\hline 1 & 1 & Test & $\begin{array}{c}\text { Memulai Aplikasi } \\
\text { Dengan Baik }\end{array}$ & $\begin{array}{c}\text { Menampilkan ke } \\
\text { splash screen dengan } \\
\text { baik }\end{array}$ & Tercapai \\
\hline 2 & 2 & Test & $\begin{array}{c}\text { Menampilkan scene } \\
\text { loading dengan cepat }\end{array}$ & $\begin{array}{c}\text { Menampilan } \\
\text { scene loading dengan } \\
\text { baik }\end{array}$ & Tercapai \\
\hline 3 & 3 & Test & $\begin{array}{c}\text { Menampilkan menu } \\
\text { pemilihan kamera AR }\end{array}$ & $\begin{array}{c}\text { Menampilkan } \\
\text { menu dengan baik }\end{array}$ & Tercapai \\
\hline 4 & 4 & Test & $\begin{array}{c}\text { Semua tombol } \\
\text { berjalan dengan baik }\end{array}$ & $\begin{array}{c}\text { Fitur berjalan } \\
\text { dengan baik }\end{array}$ & Tercapai \\
\hline 5 & 5 & Test & $\begin{array}{c}\text { Menampilkan objek } \\
\text { 3D }\end{array}$ & $\begin{array}{c}\text { Fitur berjalan } \\
\text { dengan baik }\end{array}$ & Tercapai \\
\hline
\end{tabular}

Berdasarkan hasil dari tabel pengujian diatas dapat diketahui tingkat ketercapaian dalam segala test yang di lakukan di atas adalah tercapai dan sangat baik.

\section{UMKM}

UMKM adalah sebuah aktivitas ataupun kegiatan ekonomi yang telah menjadi penggerak suatu pembangunan sebuah negara. Seperti halnya industri, agraris, agribisnis, manufaktur, dan juga sumber daya manusia. Penjelasan ini dapat diindetifikasi bahwa UMKM (Usaha Mikro, Kecil, dan Menengah) dapat mengandung suatu arti sebagai 
pemulihan perekonomian sebuah negara yang melalui pengembangan dari berbagai sektor perdagangan untuk suatu program pemberdayaa masyarakat yang memerlukan suatu pekerjaan.

Pemimpin suatu perusahaan sering membuat visi setelah usahanya berjalan bebrapa tahun. Hal ini wajar karena belum ada kepastian dan pengalaman membuat visi yang sesuai dan tepat dengan bisnis yang berhasil dilanjutkan berumur panjang. Alasan kedua bahwa visi dibuat belakangan karena pada umumnya usaha mikro tidak dilakukan melalui studi kelayakan yang ilmiah dengan proyeksi 5 sampai 10 tahun. Pada umumnya usaha mikro dibuat berdasarkan intuisi, ramalan atas keyakinan diri sendiri berdasarkan kekuatan yang telah ada di tangan. Para pengusaha-mula (start up) acapkali melakukan uji coba pada suatu bidang usaha, kemudian dihentikan karena pertumbuhannya yang lambat [1]-[2].

\section{E. Android}

Android adalah sebuah sistem operasi yang telah banyak digunakan pada suatu perangkat yang telah terkenal dan begitu popular yang biasa dipergunakan pada berbagai macam-macam ponsel . Android ialah sebuah platform pemrograman dan telah dikembangkan oleh perusahaan Google untuk berbagai macam ponsel maupun perangkat seluler lainnya, contohnya tablet dan handphone. Android juga dapat berjalan dengan berbagai macam perangkat yang telah dikembangkan oleh berbagai vendor ponsel yang ada disuatu negara.

Android merupakan sebuah sistem operasi yang open source, dan Google telah merilis berbagai macam kode dengan menggunakan Lisensi Apache, untuk kode open source dan lisensi perizinan terdapat dalam Android yang memungkinan suatu perangkat lunak agar bisa lebih mudah dimodifikasi dengan bebas dan juga dapat didistribusi oleh para device maker, operator, serta pengembang aplikasi lainnya. Android juga memiliki beberapa komunitas dari para pengembang aplikasi (apps). [3]-[4].

\section{F. Augmented Reality}

Augmented Reality dapat menambah suatu informasi dan arti untuk sebuah objek di ruang nyata. Tidak seperti virtual reality, augmented reality tidak dapat membuat simulasi kenyataan (simulation of reality),namun sebaliknya, augmented reality membutuhkan sebuah objek atau ruang yang nyata sebagai pondasi untuk menambahkan sebuah data kontekstual yang dapat mempermudah pemahaman seseorang terhadap suatu objek.[5]-[7].

\section{G. Vuforia}

Vuforia merupakan plugin dari suatu software yang bernama Unity 3D. Agar dapat membuat sebuah aplikasi Augmented Reality, pembuat harus menyiapkan beberapa komponen-komponen seperti model 3 dimensi suatu objek yang nantinya akan muncul saat pattern yang akan di-scan, model 3 dimensi dapat dibuat melalui sebuah aplikasi Blender maupun berbagai macam program modeling 3 dimensi lainnya. Augmented Reality juga membutuhkan sebuah gambar 2 dimensi untuk dapat digunakan sebagai pattern, model 2 dimensi dapat dibuat melalui berbagai macam software seperti CorelDraw, Photoshop, maupun Paint [8].

\section{H. Blender}

Blender ialah sebuah software pembuat sebuah objek 3 dimensi yang mampu membuat suatu model atau animasi. Pengguna bisa memanfaatkan aplikasi Blender untuk sebuah game engine, atau bisa disebut software aplikasi untuk membuat sebuah game. Pengguna dapat mendapatkan software aplikasi Blender secara gratis atau tidak perlu biaya apapun di web resminya yaitu www.blender.org. Blender dapat tersedia untuk sistem operasi 32bit maupun 64bit untuk Windows maupun Linux. Tetapi, untuk saat ini software aplikasi Blender sudah tidak bisa digunakan pada sistem operasi Windows XP, untuk aplikasi Blender sendiri ialah sebuah software yang dapat membuat sebuah tampilan 3 dimensi dan ukuran file tidak lebih 100MB. Oleh karena itu, pengguna dapat menjalankan aplikasi Blender ini disebuah perangkat komputer yang spesifikasinya terlalu tinggi [9].

\section{UML (Unified Modelling Language)}

Unified Modelling Language merupakan suatu bahasa standar yang digunakan untuk menjelaskan atau memvisualisasi suatu artifak dari proses analisa dan desain yang berorientasi objek. UML ini memungkinkan pembuat untuk dapat melakukan permodelan secara visual, untuk penekanan pada suatu penggambaran bukan yang didominasi oleh sebuah narasi.[10]

\section{KESIMPULAN}

Aplikasi ini dapat memenuhi tujuan awal dari pembuatan ialah sebuah aplikasi augmented reality yang dapat memunculkan produk UMKM berupa tampilan objek 3 dimensi virtual, aplikasi augmented reality produk UMKM ini dapat memudahkan produsen untuk mengenalkan produk mereka pada konsumen. 


\section{UCAPAN TERIMA KASIH}

Terima kasih ayahku dan ibuku yang telah mengisi hari-hariku dan duniaku dengan begitu banyak kebahagiaan, sehingga seumur hidupku tidak cukup untuk menikmati semua yang kau beri, karena kalian berdua hidup ini terasa begitu mudah,indah dan penuh kebahagiaan, tidak lupa terimah kasih karena selalu menjaga diriku dalam doa-doa mu.

\section{REFERENSI}

[1] Dr. Dindin Abdurohim BS, S.Sos., MM., M.Si. 2020. Strategi Pengembangan Kelembagaan UMKM. Yogyakarta : Bintang Pustaka

[2] [Dr. Parlagutan Silitonga S.H., M.M., M.B.A. 2017. Manajemen UMKM Dan Sumber Daya Manusia. Yogyakarta : Andi Offset

[3] Herlinah, S.Kom, M.Si., Musliadi KH, S.Kom. 2019. Pemrograman Aplikasi Android dengan Android Studio, Photoshop, dan Audition. Jakarta : Gramedia.

[4] Jubilee Enterprise. 2015. Mengenal Dasar-Dasar Pemrograman Android. Jakarta : Gramedia

[5] Utomo, Dimas Setyo, Issa Arwani, Wibisono Sukmo Wardhono. 2017. Implementasi Mobile Augmented Reality Pada Aplikasi Pemilihan Sarana Dan Prasarana Laboratorium Sekolah Menengah Atas. "Jurnal Pengembangan Teknologi Informasi Dan Ilmu Komputer 1 (3)”.

[6] Ilmawan Mustaqim. 2016. Pemanfaatan Augmented Reality Sebagai Media Pembelajaran. “Jurnal Pendidikan Teknologi dan Kejuruan Vol.13, No.2"

[7] Andre Kurniawan Pamoedji, Maryuni, Ridwan Sanjaya. 2017. Mudah Membuat Game Augmented Reality (AR) dan Virtual Reality (VR) dengan Unity 3D. Gramedia

[8] Ani Ismayani. 2020. Membuat Sendiri Aplikasi Augmented Reality. Jakarta : Gramedia

[9] Ali Zaky. 2016. Animasi karakter dengan Blender dan Unity. Jakarta : Gramedia

[10] Julius Hermawan. 2014. Analisa Desain \& Pemrograman Berorientasi Obyek dengan UML dan Visual Basic.NET. Yogyakarta: Andi 